\title{
Job market signals and signs
}

\author{
Jorge M. Streb*
}

May 2007

\begin{abstract}
Under two-dimensional asymmetric information, education is a noisy job-market signal, so supplementary information is needed to determine a worker's ability. On-the-job interaction reveals a worker's productivity to the employer. Signs like employment relationships or promotions may reveal this private information to the market. Unlike signals, a worker does not voluntarily select signs. We analyze in particular one sign, employment relationships, finding they only lead to public revelation of productivity if wages are sticky. When jobmarket signs are noisy, education is valuable for high-ability workers as a life-time job market signal.

Key words: signals, signs, employment policy, wage policy, twodimensional asymmetric information
\end{abstract}

JEL codes: J31, D10

${ }^{*}$ I warmly thank the stimulating and insightful suggestions from George Akerlof, Walter Cont, Mariana Conte Grand, Gustavo Maradona, Alejandro Saporiti, Gustavo Torrens and Federico Weinschelbaum, as well as helpful comments by Ignacio Armando, Leandro Arozamena, Martin Besfamille, Federico Echenique, Alvaro Forteza, Leonardo Gasparini, Enrique Kawamura, Walter Sosa Escudero, Mariano Tommasi and workshop participants. Earlier versions of this paper were presented at UCEMA, UTDT, Universidad de la República, UdeSA, UNLP, and IAE, as well as at meetings of the BCU in Montevideo and the AAEP in Mendoza and Salta. I am responsible for all errors and omissions, and my views do not necessarily represent those of Universidad del CEMA. Jorge M. Streb, Universidad del CEMA, Av. Córdoba 374, C1054AAP Buenos Aires, Argentina; e-mail jms@cema.edu.ar; tel. 54-11-6314-3000. 


\section{Introduction}

What happens to job-market signals when individuals differ not only in ability but also in other personal traits? We specifically posit that the costs of signaling depend on the taste for study. However, the costs of signaling might differ for a host of other reasons that affect the utility cost of education, like differences in time preferences, in the income of parents, or getting married young and having to raise a family. As long as these factors do not directly affect work productivity, from the point of view of firms they are simply noise.

Since the taste for study is part of personal preferences, this is private information that has to be inferred from actions, just like ability. Once this noise is taken into account, does education still act as a separating signal? With two types of ability and two types of taste for study, we show a separating equilibrium still exists under two-dimensional asymmetric information if an extended single crossing condition is satisfied. However, no separating equilibrium exists when it is violated. Rather, there are partially pooling equilibria in which the probability the worker is more productive is monotonically increasing in the signal. Though signaling is still somewhat informative, only extreme types can be told apart. ${ }^{1}$

If there is asymmetric information on other dimensions of workers' characteristics that make education a noisy signal, employers need supplementary information to sort out the productivity of workers. Work experience is empirically important in job interviews (Behrenz 2001).

While the signaling role of education might be specially important on entry to the job market, later on employers could rely more on the jobmarket record for information. To explore this implication and separate the

\footnotetext{
${ }^{1}$ This two-dimensional asymmetric information framework with four types of agents, more or less productive workers with a taste for study or not, is complementary to Riley (2001). Riley considers an extension of the original Spence model where there are also four types of agents, because some less productive workers have relatively low signaling costs in terms of education, to analyze the consequences of introducing "noise". However, Riley's focus is on equilibrium refinements. His main point is that the intuitive criterion no longer selects a unique partially pooling equilibrium. He goes on to analyze other equilibrium refinements to define out-of-equilibrium events, and emphasizes that, as in screening models, the distribution of types is key in determining the existence of a unique equilibrium. We do not try to tackle the problem of coordinating among the equilibria. Rather, we develop a framework to integrate the influence of different types of information on earnings.
} 
earlier and later job career, we embed the signaling game in a two-period framework. Our approach links Spence's (1973) view where workers have private information about themselves, with Waldman's (1984) view where an employer has private information about its employees.

In relation to types of information, Spence (1973) distinguishes between indices and signals. Indices are fixed attributes of job applicants, unalterable observable attributes such as race and sex. Since age does not change at the discretion of the individual, Spence also considers it an index. Signals are observable characteristics that are subject to the manipulation by the individual, of which education was singled out by Spence.

As to other sources of information, employers get to know a worker through day to day contact at work. On-the-job performance generates private information that allows to assess a worker's type better. This information is not subject to the direct manipulation of the worker. From the point of view of the worker, it is an involuntary "sign" generated along the work career that indicates underlying characteristics. This definition is consistent with the usage in psychology and medicine, where a sign is an indication of the characteristics or state of an individual observable on inspection. ${ }^{2}$

This private information will affect employment relationships or promotions, which may in turn act as an informational sign that conveys this information to the whole job market. ${ }^{3}$ Employment relationships in particular may be compared to lending relationships in the credit market. The creditworthiness of small firms or individuals may only be privately known to the lender that has developed a relationship. However, the very existence of a relationship, if it is observable, can act as a public sign to third parties of who is a good credit or not. Getting a credit card or a loan can act as a good sign, and other financial intermediaries may try to get these clients. ${ }^{4}$

\footnotetext{
${ }^{2}$ In psychology and medicine, the focus is on indications of health, and in particular on indications of disease, illness, injury, or that something is not right in the body or mind. The American Cancer Society, for example, refers to a "sign" as an indication of the body that is observable by a doctor, nurse, or other health care professional, as distinct from "symptoms" that are felt or noticed by a person, but may not easily be noticed by anyone else. In this definition, "signs" mean something to the trained observer. In the case of the job market, the observers are also professionals: the current and prospective employers.

${ }^{3}$ In terms of game theory, dismissals are signals insofar as they reveal the employer's private information about the employee's type (Gibbons and Katz 1991). The distinction we draw is that, from the viewpoint of the employee, dismissals are not signals because they are not voluntarily sent by the employee.

${ }^{4}$ In my personal experience, several credit card applications were turned down because
} 
The same may happen with people that have continued employment with a given firm, though it is not obvious how much information these employment relationships actually reveal to outsiders.

For example, Gibbons and Katz (1991) provide the insight that in a dynamic setting employment relationships may be a sign to competing firms of the quality of workers. However, they assume wages are flexible, in which case the informativeness of employment relationships is null because employers may simply reduce wages. We focus on a setup where what is observable by outsiders are wage policies, not individual wages (otherwise, the specific wage offer, rather than continuation of employment, would be the sign that conveyed most information). When competing firms observe wage policies, these signs can turn individual productivity into public information if wages are sticky, because lemons are dismissed. On the other hand, under flexible wages productivity remains private information, so the employer enjoys an informational monopoly, and education remains valuable as a life-long signal for high ability workers.

Section 2 looks at the effects of two-dimensional asymmetric information on the signaling role of education. Section 3 embeds the signaling game in a two-period setup where employment relationships may be a sign of underlying ability if wages are sticky. Section 4 links the implications of the model to the related literature. Section 5 concludes.

\section{Education as a signal}

Akerlof (1970) pointed to devices such as guarantees as a potential way to solve problems of asymmetric information. Since guarantees are less expensive for sellers of high-quality goods than for sellers of low-quality goods, in principle high-quality sellers will be more willing to provide a guarantee.

Spence (1973) showed the conditions under which a signal that is less costly for high-quality sellers may indeed lead to separating equilibria where they differentiate themselves from low-quality sellers, as well as the possibility of pooling equilibria where the two types cannot be distinguished. Our signaling model builds on Spence (1973), where education is used as a signal in the job market, abstracting completely from the contribution of education to human capital.

of lack of a previous credit record. However, after a special promotion by American Express for university students, offers from commercial banks started piling up. 
Spence (1973) introduced heterogeneity in ability, so some individuals have flatter indifference curves and are willing to go farther in terms of education for any given wage increase. In our setup, preferences can differ along two dimensions, ability and other idiosyncratic factors that affect the psychic costs of education, which for simplicity we refer to as the taste for study. Once there is heterogeneity in another dimension, this introduces noise that can make the signal less informative. Whether this affects the original Spence results will depend on what can be interpreted as the signal-to-noise ratio.

The players are workers and firms. The timing is that workers first decide the level of education, taking into account its informational role in the job market. Competitive firms then make their wage offers, based on the expected productivity of workers according to their education. ${ }^{5}$

\subsection{Preferences}

Let a workers' utility depend positively on wages $w$ and negatively on the cost of education $c$,

$$
U(w, e, \theta, \nu)=w-c(e, \theta, \nu)
$$

In turn, the utility cost of education $c$ depends on education $e$, where $e \geq 0$, worker's ability type $\theta$, and idiosyncratic factors $\nu$ such as the taste for education.

In keeping with the original Spence model, the influence of the parameters $\theta$ and $\nu$ on the costs of education are given an extremely simple formulation,

$$
c(e, \theta, \nu)=\frac{c(e)}{\theta \nu}
$$

where high ability $\theta$ and high taste for education $\nu$ both lower the costs of education, and $c^{\prime}(e)>0$ (in the figures below, we assume $c(e)=e^{2}$ for concreteness). These assumptions imply that the slope of the indifference curves in space $(e, w)$ are flatter for more able individuals (higher $\theta$ ), and for individuals fonder of education (higher $\nu$ ):

\footnotetext{
${ }^{5}$ The behavior of competitive firms can be represented by a single player that minimizes a loss function given by the quadratic difference between wages and productivity (Fudenberg and Tirole 1991, chap. 11).
} 


$$
\left.\frac{d w}{d e}\right|_{\bar{U}}=-\left.\frac{U_{e}}{U_{w}} \Rightarrow \frac{d w}{d e}\right|_{\bar{U}}=\frac{c l(e)}{\theta \nu} .
$$

Firms are risk-neutral and maximize profits. Ability type $\theta$ determines the productivity level. Profits equal a worker's productivity minus wages:

$$
\pi=\theta-w
$$

From a firm's point of view, only factor $\theta$ matters, while factor $\nu$ is irrelevant for its profits. It will, however, introduce noise into the signal. In a setting with perfectly competitive markets, expected profits will be zero, so in expected value wages will equal productivity.

\subsection{Worker heterogeneity}

We assume that ability may be either low or high, $\theta \in\left\{\theta_{1}, \theta_{2}\right\}$, and taste for education may also be low or high, $\nu \in\left\{\nu_{1}, \nu_{2}\right\}$. Heterogeneity among individuals implies that there are four types of agents, as shown in Table 1. A key assumption in what follows is that ability and taste for education are not perfectly correlated (if they were, the actual types of agents would be reduced to two).

$<$ please insert Table 1.Probability distribution in 2x2 case $>$

Let heterogeneity in taste be denoted by

$$
h \equiv \nu_{2}-\nu_{1}
$$

Denote by $\widetilde{h}$ the knife-edge case of heterogeneity that separate the intervals of what will be characterized below as high and low signal-to-noise ratios:

$$
\theta_{1}\left(\nu_{1}+\widetilde{h}\right)=\theta_{2} \nu_{1}
$$

The case $h \in[0, \widetilde{h}]$ will correspond to a high signal-to-noise ratio where tastes vary relatively less than productivity. ${ }^{6}$ The case $h \in(\widetilde{h}, H]$, for some

\footnotetext{
${ }^{6}$ In the knife-edge case $h=\widetilde{h}$, the indifference curves of types $\left(\theta_{1}, \nu_{2}\right)$ and $\left(\theta_{2}, \nu_{1}\right)$ are exactly superimposed on each other.
} 
positive $H>\widetilde{h}$, will correspond to a low signal-to-noise ratio in which tastes vary relatively more than productivity.

\subsection{Single-crossing}

If no signal were available, all workers would have a common level of zero education. In that case, firms would offer workers a wage equal to expected productivity, i.e. $w=E(\theta)$, where $E(\theta)=\left(p_{11}+p_{12}\right) \theta_{1}+\left(p_{21}+p_{22}\right) \theta_{2}$. We now analyze what happens when a signal is available to differentiate workers.

In terms of the present notation, the original Spence model corresponds to $h=0$. This case boils down to two types of workers, high and low productivity. Spence (1973) showed there are a continuum of separating equilibria. These equilibria can be characterized as perfect Bayesian equilibria. By the Cho and Kreps (1987) intuitive criterion, of all the separating signals, only the least cost signal where the low productivity worker is just indifferent between studying or not, remains; this signal is the Riley outcome (Riley 1979). There are also pooling equilibria in Spence(1973). These perfect Bayesian equilibria can be discarded applying the Cho-Kreps (1987) equilibrium dominance arguments: an able worker has lower signaling costs, so it will be willing to deviate to levels of education higher than what any less able worker would ever pick.

With one-dimensional asymmetric information, the Spence-Mirrlees singlecrossing condition asserts that the slope of the indifference curves is decreasing in $\theta$. This differential condition can be related to single crossing as an ordering of types in terms of $\theta$ (Edlin and Shannon 1998). With twodimensional asymmetric information, the marginal costs of signaling are also given by the slope of the indifference curves in (3). In our specification, these costs are inversely related to the product $\xi=\theta \nu$. The fact that the slope is decreasing in $\theta$ implies the following ordering of types:

$$
\theta_{1} \nu_{1}<\theta_{2} \nu_{1}, \quad \theta_{1} \nu_{2}<\theta_{2} \nu_{2}
$$

However, (7) is not enough to determine a complete ordering of types. The relative variation in the second dimension is crucial in determining the ranking of the marginal costs of signaling. An extension of the SpenceMirrlees condition to a two-dimensional setup is as follows: 
Definition 1 Under two dimensional heterogeneity, single-crossing in $\theta$ is satisfied if the slope of indifference curves in space $(e, w)$ (i) is decreasing in $\theta$, and (ii) does not decrease more in $\nu$ than in $\theta$.

Differentiation of (3) shows condition (i) is always satisfied (see equation 7). As to condition (ii), it is satisfied if tastes vary relatively less than productivity:

$$
\frac{\nu_{2}}{\nu_{1}} \leq \frac{\theta_{2}}{\theta_{1}}
$$

Given our multiplicative assumption about the utility function, the two dimensions can thus be projected over a one-dimensional interval. In the $2 x 2$ case, single-crossing in terms of ordering of types can thus be expressed as follows:

$$
\theta_{1} \nu_{1}<\theta_{1} \nu_{2} \leq \theta_{2} \nu_{1}<\theta_{2} \nu_{2}
$$

When (7) and (8) hold, so more productive workers indeed have flatter indifference curves than less productive workers and (9) is satisfied.

We now show that the result that the Riley outcome is the unique separating signal in the perfect Bayesian equilibria that satisfy the Cho-Kreps refinement generalizes to the interval $h \in(0, \widetilde{h}]$, which can be interpreted as an interval with a high signal-to-noise ratio. In this interval, extended single crossing holds and the ordering of types is given by (9).

If the extended single-crossing property is satisfied, beliefs $\mu($.$) on worker$ productivity in a separating equilibrium will be given by

$$
\left\{\begin{array}{l}
e=0 \quad \Rightarrow \quad \mu\left(\theta=\theta_{1} \mid e=0\right)=1 \\
e=e^{s} \Rightarrow \mu\left(\theta=\theta_{2} \mid e=e^{s}\right)=1
\end{array} .\right.
$$

For out-of-equilibrium values of education $e$, infinitely many specifications are possible. We assume a firm will expect productivity $\theta_{1}$ if $e<e^{s}$, and productivity $\theta_{2}$ if $e>e^{s}$. These beliefs determine the conditional probability a worker is productive for each observed level of education.

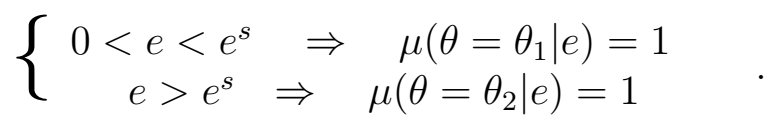


One can define $e^{s}$ by picking as signal the least-cost level of education that will differentiate more and less productive workers, as Figure 1 shows.

$<$ please insert Figure 1. Single-crossing: Separating equilibrium>

The least cost separating signal is determined by the less productive worker with a high taste for study, at point $A$ in Figure 1. At this point, worker type $\left(\theta_{1}, \nu_{2}\right)$ is indifferent between getting a high wage $w=\theta_{2}$ with education $e=e^{s}$, and a low wage $w=\theta_{1}$ with education $e=0$. It is consistent with a Nash equilibrium to assume a worker will not signal when it is just indifferent (to break indifference, it would suffice to consider a signal $e^{s}+\epsilon$, with $\epsilon>0$ that is arbitrarily small). More productive workers strictly prefer to signal and get a high wage, rather than not signal and get a low wage.

Given our specification for out-of-equilibrium beliefs, neither type of worker has an incentive to choose any other level of education because it would strictly reduce its utility. Hence, behavior will conform to (10), so this is indeed a separating equilibrium (other out-of-equilibrium beliefs are also consistent with the equilibrium strategies in 10).

The inefficient separating equilibria with levels of education $e^{s}>e$ can be discarded by application of the Cho-Kreps intuitive criterion. ${ }^{7}$ A pooling equilibrium $w=E(\theta)$, where all workers are paid the average productivity of the pool of workers, can be discarded as shown in Figure 2. This pooling equilibrium implies that, whatever the level of education, firms will infer that expected productivity is $E(\theta)$. However, the farthest that a low productivity worker is willing to deviate is point $B$, with education $e^{d}$. High productivity workers have lower signaling costs, so they can be better off to the right of that point. Since those deviations are dominated in equilibrium for less productive types but not for more productive types, by the intuitive criterion firms can infer that a worker has high productivity if levels of education larger than (or equal to) $e^{d}$ are observed. That restriction on out-of-equilibrium beliefs destroys any pooling equilibrium.

$<$ Please insert Figure 2. Single-crossing: No pooling equilibrium>

Likewise, one can discard partially pooling equilibria where some of the

\footnotetext{
${ }^{7}$ There are a multiplicity of separating equilibria with more education than $e^{s}$. However, these Perfect Bayesian equilibria do not satisfy the intuitive criterion: the out-of equilibrium beliefs would imply that low productivity workers can signal with positive probability in the interval to the right of $e^{s}$ to get a high wage, when in fact that is dominated in equilibrium by not signaling and getting a low wage. Only high productivity workers will be willing to pick signals in that interval to get a high wage.
} 
types are bunched together, namely: the three types with highest $\xi$ choose the same high signal, or the two intermediate types of $\xi$ choose the same intermediate signal, or the three types with the lowest $\xi$ pick the same low signal. The reason is that the indifference curves of more productive workers are flatter than the indifference curves of less productive types, so more productive workers will always be willing to deviate farther to the right than less productive workers to signal their type.

These results can be summarized as follows.

Proposition 2 Under two-dimensional heterogeneity, if single-crossing holds in the 2x2 case, there is a unique separating signal that satisfies the intuitive criterion. Low ability workers pick no education and high ability workers pick an education level just sufficient to signal their type. Perfect Bayesian equilibria that share these equilibrium signals may have different out-of-equilibrium beliefs.

Hence, with a high signal-to-noise ratio the signaling results of the basic Spence model are robust to two-dimensional asymmetric information. In this interval, only the Riley outcome with the undominated separating signal survives refinements of perfect Bayesian equilibria that apply the intuitive criterion.

\subsection{No single-crossing}

In the interval $h \in(\widetilde{h}, H]$, condition (8) is no longer satisfied and the ranking of the two intermediate types is inverted:

$$
\theta_{1} \nu_{1}<\theta_{2} \nu_{1}<\theta_{1} \nu_{2}<\theta_{2} \nu_{2}
$$

More productive workers no longer have lower costs of signaling. Once the extended single-crossing condition does not hold, no separating equilibrium exists. Why not is easy to see from Figure 3: a worker of type $\left(\theta_{2}, \nu_{1}\right)$ is not willing to go farther than point $C$ in Figure 3, while a worker of type $\left(\theta_{1}, \nu_{2}\right)$ is. That is, when the ranking is inverted, a less productive worker with high taste for study is willing to invest in more education than a productive worker with low taste for study.

<please insert Figure 3. No single-crossing: No separating equilibrium> 
A pooling equilibrium can be discarded as before by application of the intuitive criterion: a productive worker of type $\left(\theta_{2}, \nu_{2}\right)$ will always be willing to deviate. A partially pooling equilibrium where type $\left(\theta_{1}, \nu_{1}\right)$ worker picks zero education and the other three types with highest $\xi$ pick a common positive level of education can be ruled out by a similar argument. However, two other logical possibilities for partially pooling equilibria cannot be ruled out. First, intermediate types pick an intermediate level of education, while other types pick either zero or high education. Second, all types except $\left(\theta_{2}, \nu_{2}\right)$ pick zero education.

First, consider a partially pooling equilibrium with three signals. Type $\left(\theta_{1}, \nu_{1}\right)$ picks zero education, $e=0$. Intermediate worker types $\left(\theta_{1}, \nu_{2}\right)$ and $\left(\theta_{2}, \nu_{1}\right)$ send the same intermediate signal $e^{i}$. Finally, type $\left(\theta_{2}, \nu_{2}\right)$ picks the highest level of education $e^{s}$. Beliefs $\mu($.$) are given by:$

$$
\left\{\begin{array}{c}
e=0 \Rightarrow \mu\left(\theta=\theta_{1} \mid e=0\right)=1 \\
e=e^{i} \Rightarrow \mu\left(\theta=\theta_{1} \mid e=e^{i}\right)=\frac{p_{12}}{p_{12}+p_{21}}
\end{array} .\right.
$$

For out-of-equilibrium levels of education, we assume expected productivity equals that of the lowest level of education within each interval (again, other specifications are also possible). Out-of-equilibrium beliefs are:

$$
\left\{\begin{array}{c}
0<e<e^{i} \quad \Rightarrow \quad \mu\left(\theta=\theta_{1} \mid e\right)=1 \\
e^{i<e<e^{s}} \quad \Rightarrow \quad \mu\left(\theta=\theta_{1} \mid e\right)=\frac{p_{12}}{p_{12}+p_{21}} \\
e>e^{s} \quad \Rightarrow \quad \mu\left(\theta=\theta_{2} \mid e\right)=1
\end{array}\right.
$$

Expected productivity if an individual has intermediate education is $E[\theta \mid e=$ $\left.e^{i}\right]=\frac{p_{12} \theta_{1}+p_{21} \theta_{2}}{p_{12}+p_{21}}$. The equilibrium with the least-cost signals $e^{i}$ and $e^{s}$ is represented graphically in Figure 4 , where $\theta^{i} \equiv \frac{p_{12} \theta_{1}+p_{21} \theta_{2}}{p_{12}+p_{21}}$.

$<$ please insert Figure 4. No single-crossing: Partially pooling equilibrium $>$

In the spirit of the Riley outcome, let the least-cost intermediate signal be determined at point $D$, with education $e=e^{i}$ and average wage $w^{i}=\theta^{i}$, on the indifference curve of type $\left(\theta_{1}, \nu_{1}\right)$ that goes through point $e=0$ and $w=\theta_{1}$. And let the least-cost high signal be determined at point $E$, where type $\left(\theta_{1}, \nu_{2}\right)$ is just indifferent between point $D$ and education $e=e^{s}$ with wage $w=\theta_{2}$. It is easy to show that no type will want to deviate. Given these levels of expected productivity, firms will be willing to actually pay 
these wages. The equilibrium signals can also be supported by different outof-equilibrium beliefs.

Besides these least-cost signals, there are Perfect Bayesian equilibria with excess education. Just as Cho and Kreps (1987) remark for the Spence signaling model with three types of productivity that the intuitive criterion is not always strong enough to ensure the Riley outcome, the same happens in this extended setup. ${ }^{8}$

Second, for some parameter values there might be a partially pooling equilibrium where the three types with lowest $\xi$ pick zero education, and type $\left(\theta_{2}, \nu_{2}\right)$ picks a positive level of education $e^{s} .{ }^{9}$ Let equilibrium beliefs be:

$$
\left\{\begin{array}{rl}
e=0 & \Rightarrow \quad \mu\left(\theta=\theta_{1} \mid e=0\right)=\frac{p_{11}+p_{12}}{p_{11}+p_{12}+p_{21}}
\end{array} .\right.
$$

For out-of-equilibrium levels of education, we assume expected productivity equals that at the lowest level of education within each interval. Outof-equilibrium beliefs are:

$$
\left\{\begin{array}{rl}
0<e<e^{s} \Rightarrow \mu\left(\theta=\theta_{1} \mid e\right)=\frac{p_{11}+p_{12}}{p_{11}+p_{12}+p_{21}} \\
e>e^{s}
\end{array} \quad \Rightarrow \quad \mu\left(\theta=\theta_{2} \mid e\right) \stackrel{1}{=} .\right.
$$

Expected productivity if an individual has no education is $E[\theta \mid e=0]=$ $\frac{\left(p_{11}+p_{12}\right) \theta_{1}+p_{21} \theta_{2}}{p_{11}+p_{12}+p_{21}}$. The partially pooling equilibrium with the least-cost signal $e^{s}$ can be constructed by an argument similar to Figure 4 . This is a perfect

\footnotetext{
${ }^{8}$ Here, an intermediate signal in the range between point $D$ in Figure 4 and the point where the indifference curve of type $\left(\theta_{2}, \nu_{1}\right)$ through coordinates $\left(0, \theta_{1}\right)$ cuts the intermediate wage line (call it $D^{\prime}$ ) may also satisfy (13), with the high signal now determined where the indifference curve of type $\left(\theta_{1}, \nu_{2}\right)$ through point $D \prime$ cuts the high wage line (call this point $E \prime)$. The only equilibria that can be ruled out over the interval $[D, D \prime]$ are those where the highest possible wage for type $\left(\theta_{1}, \nu_{1}\right), w=\theta_{2}$, is at an education level that leads to a point below the indifference curve that gives this type its equilibrium payoff. In that case, equilibrium dominance arguments can be used to rule out this type. However, since indifference curves of type $\left(\theta_{1}, \nu_{1}\right)$ do not become vertical at $D$, there always remains a non-empty interval to the right of $D$ over which equilibrium dominance arguments have no bite.

${ }^{9}$ I thank Gustavo Maradona for pointing this out.
} 
Bayesian equilibrium because no type of worker is willing to deviate. Additionally, there are other equilibria that are less efficient, so the signal is not unique. $^{10}$

The intuitive criterion is not always capable of ruling out partially pooling equilibrium (15). Let $\theta^{\text {low }} \equiv \frac{\left(p_{11}+p_{12}\right) \theta_{1}+p_{21} \theta_{2}}{p_{11}+p_{12}+p_{21}}$, and $\theta^{i} \equiv \frac{p_{12} \theta_{1}+p_{21} \theta_{2}}{p_{12}+p_{21}}$. It is possible to rule out this equilibrium if the education-wage pair $\left(e^{d}, \theta_{2}\right)$ that leaves type $\left(\theta_{1}, \nu_{1}\right)$ indifferent to education-wage pair $\left(0, \theta^{\text {low }}\right)$ is such that type $\left(\theta_{2}, \nu_{1}\right)$ prefers $\left(e^{d}, \theta^{i}\right)$ to alternative $\left(0, \theta^{\text {low }}\right)$. Figure 5 illustrates the case when it is possible to rule out this equilibrium. This will depend on specific parameter values, requiring sufficiently large $\theta_{2}$ or sufficiently small $\frac{p_{12}}{p_{12}+p_{21}}$.

$<$ please insert Figure 5. No single-crossing: Alternative partially pooling equilibrium?>

Consequently, we have established the following result:

Proposition 3 Under two-dimensional heterogeneity, if single-crossing does not hold in the 2x2 case, the equilibrium signals that satisfy the intuitive criterion are not unique. One possibility is that low $\theta$ and $\nu$ types pick no education, intermediate types pick intermediate education, and high $\theta$ and $\nu$ types pick high education. Besides the undominated signals, signals with excess education are possible. For some parameter values, high $\theta$ and $\nu$ types may pick high education, while the rest pick low education. Perfect Bayesian equilibria that share the same equilibrium signals may have different out-ofequilibrium beliefs.

From the viewpoint of firms, parameter $\nu$ basically introduces noise into the signal. The setup without single-crossing can be interpreted as a case of a low signal-to-noise ratio. Proposition 2 implies that extreme signals are still effective in conveying a workers' type. It is in the middle ground, which may include all but the most able and motivated employees, that there is noise and imperfect revelation of type.

As to the relevance of a partially pooling equilibrium, the Appendix analyzes the extended single-crossing condition in the $N x N$ case: for a given

\footnotetext{
${ }^{10}$ Namely, it is possible to have equilibria where the three types with lowest $\xi$ pick some positive level of education, together with out-of-equilibrium beliefs that assign individuals with no education low productivity. These socially less efficient equilibria cannot be discarded by the intuitive criterion.
} 
range of variation of productivity, as the number $N-2$ of intermediate productivity types grows, it becomes impossible to satisfy single-crossing unless the range of variation in the second dimension shrinks faster (and disappears in the limit). How serious the issue of noise is will depend on the relative range of variation of each dimension: perhaps only close productivity types are bunched together, or instead very distant productivity types are.

\section{$3 \quad$ Employment relationships as signs}

If education is indeed a noisy signal, signaling via education will lead to a partially pooling equilibrium. This information could be specially relevant to determine entry requirements (again, we are abstracting from the role of education in the buildup of human capital, that enhances productivity in itself). Afterwards, one would expect firms to use other types of information to sort productive and unproductive workers. In this regard, we explore the role of employment relationships.

The informativeness of employment relationships may depend on the wage-setting process. We consider two polar cases, sticky and flexible wages. As to their relevance, Gottschalk (2005) explains a lot of the evidence on nominal wage flexibility in terms of measurement error. Bewley (2002) reports that wage cuts, defined as the reduction in the pay of an employee continuing to work under unchanged conditions, is low according to surveys of employers from several countries, and is negligible in the few existing studies of company records. The arrangements on sticky wages may depend on fairness considerations, as in the Akerlof and Yellen (1988) fair wage/effort hypothesis. Indeed, Bewley (2002) reports that surveys of business managers responsible for compensation policy show that employers avoid cutting pay because doing so would hurt morale and goodwill, and hence productivity. It may well be that different corporations follow different norms of fairness, so not all need apply the same policy. Nevertheless, if most notions of fairness consider wage cuts unfair and lead to a reduction of work effort, this could lead to a prevalence of sticky wages in most firms.

Even if nominal wages are mostly sticky, an inflationary environment helps to flexibilize real wages, which are the relevant variable for the dismissal decision. Indeed, though nominal wage cuts are often considered unfair, the same does not hold for real wage cuts when inflation is positive (Tversky and Kahneman 1986). In this regard, Gibbons and Waldman (1999) mention 
several studies that show real wage decreases are not rare, though demotions are.

The process of revelation of productivity at work takes time, so to incorporate this feature requires a minimum of dynamics. We assume there are two periods. The first period represents the early work career, while the second period represents the later work career. A workers' utility depends on wages $w^{t}$ in periods $t=1,2$, as well as on the cost of education $c$. The parameter $\delta$ represents the discount factor, which determines the relative importance of the early and late work career:

$$
U\left(w^{1}, w^{2}, e, \theta, \nu\right)=w^{1}+\delta w^{2}-c(e, \theta, \nu)
$$

In the first period, the worker has private information on its productivity and signals with a given education level. Firms then make job offers conditional on educational levels. After the first period has elapsed, the employer observes the worker's true productivity. Employment relationships may turn this private information into public information in the second period.

Rather than analyze wage decisions, we will focus on the choice of the employer among wage policies. That is, an employer will set a rule, conditional on a worker's productivity, that will determine whether the wage is changed or not in the second period. A given wage policy can be seen as an ex-ante commitment that defines what an employer will do when productivity is revealed. We will require the wage rule to be credible ex-post. The employer also follows an employment policy that determines employment relationships.

The informational requirements for competing firms of observing the employer's wage policy are smaller than observing wage decisions, because they do not need to know the specific wages that each employee is receiving. Furthermore, if competing firms observed each individual wage offer, this would provide additional information on employees that goes beyond the information contained in the employment relationship. For comparability with other approaches, we will briefly analyze below what happens when wages are observable.

When the first-period educational signal does not affect second-period earnings, both periods can be analyzed independently. That is, if education only affects wages in the first period, the first period equilibrium can be analyzed as in Section 2, where the interpretation is now that the costs of education have to be compared to the benefits in the early job career (period 
one). However, this is not always possible. Hence, our approach will be to solve the second-period game conditional on a given signaling equilibrium in the first period. We will then compute the first-period signals taking into consideration first- and second-period payoffs.

\subsection{Sticky wages}

Suppose that wages are sticky, so firms cannot reduce the wages of their employees. In the context of this restriction, a firm that maximizes profits might want to dismiss (lay off or fire) in the second period workers whose first-period contract stipulates a wage larger than their productivity. To not enter into the issue of the duration of unemployment spells, we will simply assume that either there is a sign of continued employment relationship or not.

In the second period, the timing is that the informed firm (the employer) decides its employment policy, setting a cutoff productivity level below which workers are dismissed. For those workers who qualify for a renewal of their contract, the employer determines a wage policy conditional on worker type (the employer can offer a wage hike). The competing firm (that represents the competitive market) observes the employment policy and the wage policy, and takes this information into account when defining its wage policy. Finally, the employer observes true productivity, which will determine whether the worker is dismissed or not, and workers who are not dismissed have to decide between staying on the job or switching firms.

We can solve the second-period game by backwards induction, conditional on a first-period equilibrium. In the second period, workers will accept the highest job offer they get (we assume that if workers are indifferent, they do not switch jobs). We first consider the case when the single-crossing condition (9) is satisfied in the first period, and then the case when it is violated.

It is immediate to see what happens if there is single-crossing, so the first-period equilibrium is separating (i.e., first-period earnings only make education worthwhile for high ability workers): if first-period wages equal the productivity of each worker, competing firms will be willing to pay that same wage in the second period. Anticipating this, in the second period the employer will renew the contracts of all workers, offering to pay the same wage as in the first period. Given this second period outcome, in the first period high ability workers will be willing to study, and low ability workers 
will not study. ${ }^{11}$

On the other hand, if single-crossing is violated, the first-period equilibrium may be partially pooling. We consider the equilibrium in (13), where there are three signals. ${ }^{12}$ For workers with either no education or high education, the employer will be willing to pay the same wage as in period one, because competing firms will match those wages. Hence, we concentrate on workers with intermediate education. Figure 6 depicts the options the employer faces. We consider three employment policies for these workers: dismiss them all $(d, d)$, dismiss less productive workers $\theta_{1}$ whose productivity is below their first-period wage $(d, n)$, or not dismiss anybody $(n, n)$.

$<$ please insert Figure 6. Employment and wage policies of informed and outside firms $>$

Because there are only two types of productivity, the policy of dismissing less productive workers $(d, n)$ will indicate that dismissed workers have low productivity, and the rest have high productivity (we show below that employer will not prefer alternative employment policies). The outside firm can condition its wage offer on whether the worker is dismissed or not: it will be willing to pay dismissed workers a low wage $\theta_{1}$, and continuing workers a high wage $\theta_{2}$. Consequently, the employer has to offer its more productive workers a second-period wage equal to their productivity: high ability workers get a high wage and low ability workers a low wage, which equals their respective productivity. This means that the employer will make zero profits on its continuing employees.

We can now analyze the first period. The solution is straightforward because dismissals always reveal the employer's private information: the key observation is that when second-period earnings depend on underlying ability, which is fully revealed to the market by employment relationships, secondperiod wages are independent of first-period education. Hence, the signaling game in the first period can be analyzed independently from the employment game in the second period, because it only affects first-period earnings.

\footnotetext{
${ }^{11}$ Low ability workers do not have an incentive to deviate. If they chose to mimic the educational signal of high ability workers, they would enjoy higher earnings in the first period, but firms would pay them a low wage in the second period. Since Proposition 2 shows that first-period earnings alone are not enough to tempt them to signal, they do not study. By a similar argument, high ability workers do not have an incentive to deviate and not study.

${ }^{12}$ For some parameter values, partially pooling equilibrium (15) with two signals is also possible. The analysis would be similar to that in text.
} 
One last point. As to alternative employment polices, foreseeing that dismissals reveal productivity, employers could decide not to dismiss anybody. Indeed, as an alternative, the employer can keep all workers, paying them $\theta^{i}$ (if it payed more, in expected value it would lose money). The outside firm will be willing to match that, since it will make zero profits. The employer can also dismiss all workers, in which case the outside firm will be willing to pay them their expected productivity $\theta^{i}$. Since any of the three employment policies in Figure 6 leads to zero expected profits, the employer is in principle indifferent among them ex-ante. However, the equilibria where employment relationships do not reveal an employers private information on productivity are not credible ex-post, so we discard them. ${ }^{13}$ Hence,

Proposition 4 If wages are sticky, with 2 productivity types employment relationships reveal an employer's private information on productivity. Secondperiod earnings equal productivity, and education only affects first-period earnings.

\subsection{Flexible wages}

What happens if firms can reduce the wages of employees who are found to have low productivity? In that case, the competing firm will not be able to distinguish high and low productivity workers by their employment relationships, because there is no need of dismissing unproductive workers.

The second period timing is that the employer first decides its wage policy. The employer can condition its wage offer on the productivity type each employee has. The second-period offer may be either larger or smaller than the first period wage since there are no restrictions on wage cuts. The uninformed firm does not observe the exact offer the informed firm makes to each employee, but it observes the wage policy, in terms of what wages are offered to each type of worker. On the basis of the employer's wage policy, competing firms make the employees a counteroffer, which they cannot con-

\footnotetext{
${ }^{13}$ Ex-post, the employer may want to switch policies: if revealed productivity of its employees with intermediate education were below the first period wage, it would not want to keep them all; if revealed productivity were above the first period wage, it would not want to dismiss them all. Furthermore, beyond 2 productivity types the employment policy of discriminating between low and high productivity workers will provide positive rents, so it will be strictly preferred by the employer to policies where expected profits are always zero.
} 
dition on the worker's type because this is inside information. Finally, each type of worker has to decide between staying on the job or switching firms.

We can solve the second-period game by backwards induction. Workers will accept the highest job offer they get. We assume that workers who are indifferent do not switch jobs. Again, it is immediate to see what happens if there is single-crossing, so the first-period equilibrium is separating. Competing firms will be willing to pay the first-period wages, which equal productivity. The employer will match that, offering a renewal of contracts. Given this second period outcome, in the first period high ability workers will indeed be willing to study, and low ability workers will not study.

On the other hand, if single-crossing is violated, the first-period equilibrium may be partially pooling, with a signal of intermediate education that corresponds to a mix of more and less productive workers. In the second period, less productive workers will face a wage cut, since the employer will not be willing to pay more than $\theta_{1}$. However, the employer has more options for more productive workers $\theta_{2}$ : schematically, it can offer to raise the wage, to reduce it, or to maintain it at level of first-period wage $\theta^{i}=\frac{p_{12} \theta_{1}+p_{21} \theta_{2}}{p_{12}+p_{21}}$. This is represented in Figure 7.

$<$ please insert Figure 7. Wage policies of informed and uninformed firms $>$

For simplicity, the representation is restricted to conditional strategies where the informed firm always offers low productivity workers a low wage. On the other hand, it can offer high productivity workers either the same wage $\theta^{i}$ as in the first period, a low wage $\theta_{1}$ (the same logic will apply to any other low wage), or a high wage $\theta_{2}$ (the same logic will apply to any other high wage). As to the unconditional strategies of uninformed firms, they can offer wages between $\theta_{1}$ and $\theta^{i}$ (any wage higher than $\theta^{i}$ would lead them to lose money). For simplicity, we only represent the two endpoints.

In view of these logical possibilities, if the employer offers type $\theta_{2}$ employees a raise above $\theta^{i}$, uninformed firms will have an incentive to offer a low wage equal to $\theta_{1}$, because at any wage equal to or lower than the expected productivity of the pool of workers with intermediate education they will only attract lemons, losing money. If the employer offers type $\theta_{2}$ employees a wage reduction below $\theta^{i}$, uninformed firms can offer all workers a wage that is slightly higher (up to $\theta^{i}$ ), attracting the whole pool and still making a profit. The last possibility is to offer type $\theta_{2}$ employees the same wage $\theta^{i}$ as in period one. If we assume for simplicity that a worker does not switch jobs when indifferent (to not have to add $\varepsilon$ to break tie), then uninformed firms have an incentive to offer a low wage equal to $\theta_{1}$ : at a wage equal to average 
productivity $\theta^{i}$ of pool they would only attract lemons, loosing money.

Given this maximizing behavior of uninformed firms, namely, offering $\theta^{i}$ to pool of workers if the employer offers more productive workers less than $\theta^{i}$, and offering $\theta_{1}$ if employer offers them $\theta^{i}$ or more, the informed firm has an incentive to pick the conditional strategy of offering type $\theta_{1}$ workers a wage equal to their productivity $\theta_{1}$, and type $\theta_{2}$ workers the same wage $\theta^{i}$ as in the first period. Consequently,

Proposition 5 If wages are flexible, with 2 productivity types employment relationships do not reveal an employer's private information on productivity. If single-crossing holds, education leads to separating equilibrium in the first period, and second-period earnings equal productivity. If single-crossing does not hold, education may instead lead to a partially pooling equilibrium in the first period, allowing the employer informational rents on some high ability workers in the second period.

The main insight from flexible wages is that, if employers can use conditional wage strategies, information on productivity may remain private even when there are only 2 types of productivity. The employer will have an informational monopoly: the informed firms will be under no pressure to raise the wage of productive workers with intermediate education. Hence, the informed firm can engage in cream-skimming, paying more productive workers with less education below their full productivity.

The result in Proposition 5 implies that if wages are flexible, the first and second period games cannot be analyzed separately. When productivity remains private information, wages for high ability workers in the second period will not be independent of education in the first period. We turn to this now.

\subsection{Signaling, short- and long-term}

When employment relationships do not reveal a worker's productivity to the job market, a high ability worker that invests in more education in the first period earns higher wages not only in the first period, but also in the second period. On the other hand, for low ability workers education only leads to higher wages in the first period. I.e., for high ability workers $w^{2}=w^{1}$, while

for low ability workers $w^{2}=\theta_{1}$. In view of these remarks, the objective functions in the first-period signaling game can be simplified as follows: 


$$
\left\{\begin{array}{c}
\theta=\theta_{2}: U\left(w^{1}, w^{2}=w^{1}, e, \theta_{2}, \nu\right)=w^{1}(1+\delta)-c\left(e, \theta_{2}, \nu\right) \\
\theta=\theta_{1}: U\left(w^{1}, w^{2}=\theta_{1}, e, \theta_{1}, \nu\right)=w^{1}+\delta \theta_{1}-c\left(e, \theta_{1}, \nu\right)
\end{array} .\right.
$$

Furthermore, the first-period analysis has to be amended for a feature similar to Waldman (1984): with perfect competition, all workers with intermediate education will be paid a bond in the first period equal to the discounted value of the informational rent that employers will enjoy. More able workers share this bond with less able workers that also have intermediate education. The bond $b^{i}$, discounted at interest rate $r$, equals:

$$
b^{i}=\frac{p_{21}}{p_{12}+p_{21}} \frac{\theta_{2}-\theta^{i}}{1+r}=\frac{p_{21} p_{12}}{\left(p_{12}+p_{21}\right)^{2}} \frac{\theta_{2}-\theta_{1}}{1+r} .
$$

More productive workers are willing to go farther to invest in education: the educational signal affects their earnings over their whole work career, in contrast to low ability workers who only benefit in their early work career. Consequently, the indifference curves of high ability workers become flatter:

$$
\left\{\begin{array}{c}
\theta=\theta_{2}:\left.\frac{d w_{1}}{d e}\right|_{\bar{U}}=\frac{c l(e)}{(1+\delta) \theta_{2} \nu} \\
\theta=\theta_{1}:\left.\frac{d w_{1}}{d e}\right|_{\bar{U}}=\frac{c(e)}{\theta_{1} \nu}
\end{array} .\right.
$$

Figure 8 modifies Figure 4 to incorporates the long-term effects of signaling. The least-cost signals $e^{s}$ must take into account that workers with intermediate education receive a bond $b^{i}$. Since low ability types get this bond if they switch from low signal $e=0$ to intermediate signal $e^{i}$, the intermediate signal $e^{i}$ becomes larger, and the high signal $e^{s}$ smaller To represent high-ability types in the same figure, one has to reckon their permanent income, not their current income, discounting their lifetime earnings by $(1+\delta)$. With no education or high education, their permanent income $\left(w^{1}+\delta w^{2}\right) /(1+\delta)=w^{1}$, given that $w^{2}=w^{1}$; with intermediate education, their permanent income $\left(w^{1}+\delta w^{2}+b^{i}\right) /(1+\delta)=w^{1}+b^{i} /(1+\delta)$.

$<$ please insert Figure 8. No single-crossing: Partially pooling equilibrium in two-period model>

Because of the bond $b^{i}$, the condition $(1+\delta) \theta_{2} / \theta_{1}<\nu_{2} / \nu_{1}$ is not sufficient for a partially pooling equilibrium: as shown in Figure 8, the indifference 
curve of type $\left(\theta_{2}, \nu_{1}\right)$ must not only be steeper than that of type $\left(\theta_{1}, \nu_{2}\right)$, it must also intersect that curve before point $E^{\prime}$. Though a partially pooling equilibrium is less likely than in Proposition 3, because the conditions are more stringent, it is still not ruled out.

Proposition 6 When employment relationships do not reveal a worker's productivity, education is a life-time signal for high ability workers. However, if single-crossing is violated, a partially pooling equilibrium in the first period is still possible when the relative variation of $\nu$ exceeds a certain bound.

The fact that on-the-job productivity does not fully become public information might help explain the role of an MBA, where people with work experience enroll. In comparison to other graduate programs, an MBA has less of a human capital role, and more of a signaling role. Indeed, some participants in the process describe it as basically going around from one meeting to another with corporate representatives. Such a limited role can make perfect sense to those students that basically need the MBA as a system-wide signal to reveal their ability, if their work record does not accomplish that for them. By (20), high ability agents have lower signaling costs because education increases their life-time earnings; even if ability $\theta_{2}$ did not reduce the costs of education, if the condition $(1+\delta)>\nu_{2} / \nu_{1}$ is satisfied, it is sufficient to ensure a separating equilibrium. This leads to self-selection: only people who believe they are high-ability have an incentive to invest in an MBA as a job-market signal.

\section{Related literature}

\subsection{Theoretical implications}

Our results on employment relationships are at odds with the results in Gibbons and Katz (1991), who find with a continuum of productivity types that employment relationships reveal that workers with a continuing employment relationship have productivity above a certain cut-off level. Since Gibbons and Katz suppose that wages are completely flexible, the implication of the present analysis is that employment relationships should reveal nothing at all: the employer does not need to dismiss low productivity workers, it can just reduce their wages. 
Gibbons and Katz (1991) point out a theoretical conundrum: the temptation of the employer to pay all workers a low wage, regardless of their productivity, makes an equilibrium in pure strategies impossible. However, when outside firms only observe the wage polices of the employer (i.e., the conditional rules that relate wages to productivity), the employer does not need to pay all employees the same wage. Proposition 5 shows that in equilibrium the employer will refrain from cutting the wages of high ability workers.

Though our approach where competing firms observe wage policies but not individual wages may be realistic, it is not the standard approach. The usual assumption in the literature is that competing firms observe each individual wage. Observable wages implies more information for outside firms, because individual wages can convey information about each worker's type. For comparability with other approaches, we briefly review what happens when the employer follows, as before, an employment policy (i.e., a conditional rule that relates employment relationships to productivity), but then makes a wage offer that is observable by outside firms.

Under sticky wages, if wages are observable, the outcome with two productivity types is the same when the employer dismisses less productive employees and keeps more productive employees. Since outside firms offer to pay continuing workers $\theta_{2}$, whatever the wage offer of the employer, the employer has to offer continuing workers a wage of $\theta_{2}$. However, there are equilibria where employment relationships do not reveal productivity. ${ }^{14}$

Under flexible wages, if wages are observable, we run into the same stumbling block that Gibbons and Katz (1991) encountered: the employer will not want to pay a high productivity worker a higher wage than a low productivity worker, because that very offer will reveal its private information to competing firms. Hence, there is no equilibrium in pure strategies. However, this does not mean there is no wage equilibrium at all. With 2 productivity types, there is an equilibrium in mixed strategies that implies no dismissals. The employer offers a wage $\theta_{1}$ to $\theta_{1}$ type workers, and plays a mixed strategy of offering $\theta_{2}$ type workers either a wage of $\theta_{1}$ or a wage larger than $\theta_{1}$ (which

\footnotetext{
${ }^{14}$ In these equilibria, the outcome is that all workers are payed $\theta^{i}$. This is because dismissing all workers is an equilibrium, given that outside firms offer continuing workers a wage of $\theta_{2}$ when $\theta_{1}$ types are dismissed. Not dismissing any workers, offering them all $\theta^{i}$, is also an equilibrium if all workers switch to outside firms when wage offers match, an assumption opposite to that made in text (if the employer deviated, offering a higher wage to $\theta_{2}$ types, outside firms would be willing to pay them $\theta_{2}$, leaving the employer stuck with $\theta_{1}$ types at a loss). Ex-post, the employer makes zero profits in all equilibria.
} 
can be as large as $\theta_{2}$ ). The uninformed firm offers a wage equal to expected productivity of pool of workers that receive a wage offer of $\theta_{1}$, and a wage $\theta_{2}$ to workers that receive any wage offer larger than $\theta_{1}$. Given these strategies, both the employer and the uninformed firms are making zero profits, and neither has an incentive to deviate. Hence, if outside firms observe individual wages there will be no rents, instead of the positive rents when they observe wage policy. This makes sense, because an individual's wage conveys more information about an individual worker than a wage policy does. However, the feature that some $\theta_{2}$ type workers receive a wage that is less than their productivity remains.

When there are more than 2 productivity types the Appendix shows that the result in Proposition 4 on full revelation of employer's private information under sticky wages through employment relationships does not hold. What is true is that more information is always revealed under sticky wages than under flexible wages. The key intuition is that competing firms are always willing to pay the pool of continuing workers their expected productivity. The expected productivity of pool of continuing workers exceeds first-period wage under sticky wages, but equals first-period wage with flexible wages. ${ }^{15}$ The higher wage offers that competing firms are willing to make under sticky wages limit the informational rents of the informed firm.

\subsection{Empirical implications}

If the first period were only a short probationary period where the employer could gather all the relevant information on productivity, education would not be very relevant as an entry signal to the job-market. This raises the question of how extensive the early work career is in relation to the later work career. In this regard, a partially pooling equilibrium with three signals in the first period implies a growth over time of the variance of wages for higher educational levels, because in the second period some workers with

\footnotetext{
${ }^{15}$ With flexible wages, the employer can use the following wage policy when 3 or more productivity types are bunched together: pay $\theta_{1}$ types a wage of $\theta_{1}$, pay $\theta_{2}$ types a wage equal to expected productivity of pool of $\theta_{1}$ and $\theta_{2}$ types, pay $\theta_{3}$ types a wage equal to expected productivity of pool of $\theta_{1}, \theta_{2}$, and $\theta_{3}$ types, and so on. If this strategy is followed, outside firms will offer $\theta_{1}$, but with the credible threat that they will raise their offers and hire away the employees if the informed firm tries to pay its employees anything less. The analysis is similar to Figure 7 in text.
} 
intermediate education get high wages and others get low wages. ${ }^{16}$ This can be related to Mincer (1974), whose table (reproduced in Weiss 1983) is shown as Table 2. While the variance of the log of weekly earnings in Table 2 hardly changes for people with 5-8 years of schooling (excepting the 60-64 age group), for people with 12 years of schooling it rises smoothly but steadily, from .205 at ages 24-29 to .317 at ages 55-59. And for people with 16 years of schooling, where signaling can be expected to be especially important because of the more autonomous nature of jobs, the variance rises a lot, from .235 for 24-29 year-old group to .552 for 55-59 year-old group.

$<$ please insert Table 2. Variance of the log of weekly earning according to age and years of schooling $>$

Albeit indirectly, the fact that the variance in earnings for people with 16 years of schooling at first does not rise much (until ages 40-44) might indicate that the early work career could represent a period of up to 10 or 15 years.

Ashenfelter and Krueger (1994) find that returns to education for identical twins may be as large as for the population as a whole, which in the line of human capital models can be interpreted as isolating the effect of education on earnings, controlling for ability. Weiss (1995) also offers a sorting explanation: firms will infer a worker's unobserved ability from the educational choice, so education should affect initial wages according to the signaling model. Weiss goes on to say that if the signaling model is correct, the return to schooling across twins should decline over time, and he finds some evidence in that direction. However, the results above show that the implication of the signaling models critically depend on whether the employer's private information becomes public or not: if it becomes public, wage differences should decline over time, but if it doesn't, wage differences will not decline. ${ }^{17}$ The implication of private information is that wages need not match productivity, because the employer's private information leads to informational rents. In this context, education as a signal will not only affect the wages of more able workers in their early job career, but rather over their whole career.

\footnotetext{
${ }^{16}$ This would not happen in the partially pooling equilibrium with two signals. However, since for some parameter values this equilibrium does not exist, in the text we concentrate on the partially pooling equilibirum with three signals.

${ }^{17}$ In fact, the model with flexible wages implies that difference will increase, because workers with intermediate education are paid an extra bond in the first period equal to expected discounted value of the informational rent in the second period. Wages that decline over the life-cycle are counter-factual, but we are abstracting from the positive influence of experience and human capital on earnings.
} 
Under sticky wages, Table 3 shows for the $2 \times 2$ case that there is a positive correlation between education and wages: more highly educated workers on average get higher wages in the second period. Hence, even if education is a noisy signal, the standard implication of Spence (1973) stands over time. Second, there is a positive correlation between employment relationships (workers who have not been dismissed) and wages. That is, dismissed workers earn less, and this effect is important for people with more education. This is precisely the empirical pattern of layoffs and lemons so nicely studied by Gibbons and Katz (1991).

$<$ please insert Table 3. Second period wages with public information $>$

Under flexible wages, Table 4 shows that there is also a positive correlation between education and wages: more highly educated workers on average get higher wages in the second period $\left(w^{1, i}\right.$ stands for the wage that individuals with intermediate education receive in periods 1 and 2). However, workers with the same productivity and different education may earn different wages, due to the informational rents that employers enjoy.

$<$ please insert Table 4. Second period wages with private information $>$

Though sticky wages may be prevalent, inflation makes the flexible wage case empirically relevant in many situations. Furthermore, an empirical implication that follows from this is that there should be less dismissals under an inflationary environment than under stable prices, because inflation is a real-wage reducing device.

\section{Conclusions}

This paper analyzes the influence of different types of information on earnings. It starts with the implications of two-dimensional asymmetric information for job market signaling. A second dimension is already implicit in the Akerlof (1970) lemons model: there is a problem with lemons because there are some dishonest sellers who are willing to misstate the quality of their car.

Both ability and an idiosyncratic factor, called taste for study, can be either high or low. An extended single-crossing condition is satisfied when the ranking of signaling costs is dominated by ability. With single-crossing, the equilibrium is separating as in Spence (1973); without it, the equilibrium is partially pooling. When the analysis is extended beyond the $2 x 2$ case, the extended single-crossing condition that ensures education is a separating signal becomes harder to satisfy. With a continuum of types, unlike the 
case of asymmetric information in one dimension (Spence 2002), it can be shown the equilibrium with asymmetric information and heterogeneity in two dimensions will never be separating but rather partially pooling. However, signaling is resilient to the introduction of asymmetric information in two dimensions in the sense that average productivity is increasing in the degree of education. Though extreme types still send unequivocal signals, other types will be difficult to tell apart.

The second dimension captures the influence of noise on the informative content of the signal. If education is a noisy signal, it will be an imperfect proxy for a worker's productivity and firms will resort to additional information. In this regard, the work record is singled out in this paper. Interaction at the work place generates private information for the employer (Waldman 1984). This is modeled in a dynamic setting where the first period, which represents the early job career, is the signaling game. The second period represents the later job career, where employers use information from the first period to judge productivity.

One way information on work productivity observed by the employer may become public is through employment relationships. Continuity of relationships can act as a sign of high productivity to other firms if higher productivity workers are more likely to keep their job. This is the Gibbons and Katz (1991) idea on layoffs revealing lemons. In contrast to the earlier literature, we find that under flexible wages employment relationships reveal no private information at all: employers do not need to dismiss lemons, they can simply reduce their wages. However, employment relationships can be a sign to the market of which employees have high productivity with sticky wages. ${ }^{18}$ As to the informative content of employment relationships beyond the $2 x 2$ case, they are always a noisy sign. Hence, employers will enjoy an informational rent, paying some more productive workers less than their full productivity (under perfect competition, firms will in turn pay out a bond, which more able workers will have to share with the less able).

There are other signs beyond employment relationships. For example, more able workers may be assigned to jobs that are more complicated or have higher responsibility. If job hierarchies are visible to outside firms, this can act as a sign of work productivity, Waldman's (1984) idea on job

\footnotetext{
${ }^{18}$ The model completely ignores that work productivity is in part a matter of matching the right person to the right job (Jovanovic 1979). This increases the amount of asymmetric information, since a worker does not know its productivity type before hand. Dismissals will indicate a mismatch, but not necessarily that dismissed workers are lemons.
} 
assignments as a sign of productivity. ${ }^{19}$

Given the incomplete revelation of an employer's private information through job-market signs, high ability workers find education valuable as a signal not only in their early job career, but over their whole work cycle. Education can make sense for high ability workers despite the fact they might face a higher opportunity cost of studying (Weiss 1983), because this can be more than compensated by larger earnings over their complete career.

A natural extension is to combine the signaling and human capital roles of education, to derive more precise empirical implications about the effects of formal education, on-the-job training and experience (Schultz 1961, Becker 1964). Our framework might also be extended to consider the closely related issue of the influence of character on productivity. Though some traits of character like perseverance are also captured by formal education (Weiss 1995), others like honesty or team spirit are not.

\section{Appendix}

\subsection{Single-crossing in the $N x N$ case}

In the $N x N$ case, if the $\log$ of $\theta_{i}$ and $\nu_{j}, i, j=1,2, \ldots, N$ are evenly spaced, then

$$
\ln \theta_{i}=\ln \theta_{i-1}+\frac{1}{N-1} \ln \frac{\theta_{N}}{\theta_{1}}
$$

and

$$
\ln \nu_{j}=\ln \nu_{j-1}+\frac{1}{N-1} \ln \frac{\nu_{N}}{\nu_{1}}
$$

For the single-crossing condition under two-dimensional heterogeneity to be satisfied in the $N x N$ case when the log of types in each dimension are evenly spaced, a necessary and sufficient condition is that:

\footnotetext{
${ }^{19}$ Waldman makes the nice point that, with a continuum of types, job assignments will only reveal part of this private information to the market, i.e., that those assigned to the higher productivity job are above a certain ability level.
} 


$$
\frac{v_{N}}{v_{1}} \leq \frac{\theta_{N}}{\theta_{N-1}}
$$

It is necessary, because otherwise $\theta_{N-1} v_{N}>\theta_{N} v_{1}$ and there is at least one lower productivity type that is willing to go farther in terms of education than a higher productivity type. It is sufficient, because due to our assumption that the log of types is evenly spaced, $\theta_{2} / \theta_{1}=\ldots=\theta_{N-1} / \theta_{N-2}=\theta_{N} / \theta_{N-1}$, which together with $(23)$ implies that $\theta_{1} v_{N} \leq \theta_{2} v_{1}, \ldots, \theta_{N-2} v_{N} \leq \theta_{N-1} v_{1}$. Inequality (23) boils down to condition (??) for single-crossing in Section 2 when $N=2$.

Inequality (23), under our assumption of evenly-spaced types, can be rewritten as

$$
\ln \frac{v_{N}}{v_{1}} \leq \frac{1}{N-1} \ln \frac{\theta_{N}}{\theta_{1}}
$$

For a given range of variation $\left(v_{N} / v_{1}\right)$ in the second dimension, the singlecrossing condition becomes increasingly harder to satisfy as $N$ grows. Conversely, as $N$ grows without limit, the range of variation of $\nu$ has to be null for single-crossing to be satisfied.

\subsection{Employment relationships as noisy signs in $3 x 3$ case}

Consider a $3 x 3$ example, with three types of productivity $\theta_{i}$ and three types of taste for study $v_{j}, i, j=1,2,3$, where the types are evenly spaced apart so $\theta_{2} / \theta_{1}=\left(\theta_{3} / \theta_{1}\right)^{1 / 2}$ and $\nu_{2} / \nu_{1}=\left(\nu_{3} / \nu_{1}\right)^{1 / 2}$.

Assume that $v_{3} / v_{1}>\theta_{3} / \theta_{1}$, so $v_{2} / v_{1}>\theta_{2} / \theta_{1}$ and $v_{3} / v_{2}>\theta_{3} / \theta_{2}$. This is only interesting scenario where there is a qualitative difference with the $2 x 2$ case; otherwise, there is no educational signal for which workers of three types of productivity can pool together.

Two orderings are possible, either $v_{2} / v_{1}>\theta_{3} / \theta_{1}$, so ranking is basically determined by $\nu$, i.e.,

$$
\theta_{1} \nu_{1}<\theta_{2} \nu_{1}<\theta_{3} \nu_{1}<\theta_{1} \nu_{2}<\theta_{2} \nu_{2}<\theta_{3} \nu_{2}<\theta_{1} \nu_{3}<\theta_{2} \nu_{3}<\theta_{3} \nu_{3}
$$

or $v_{2} / v_{1} \leq \theta_{3} / \theta_{1}$ so ranking is given by 


$$
\theta_{1} \nu_{1}<\theta_{2} \nu_{1}<\theta_{1} \nu_{2} \leq \theta_{3} \nu_{1}<\theta_{2} \nu_{2}<\theta_{1} \nu_{3} \leq \theta_{3} \nu_{2}<\theta_{2} \nu_{3}<\theta_{3} \nu_{3}
$$

We will analyze the second case, but the first case would be similar for our purposes.

The distribution of types detailed in Table 5 will determine how the different types group.

$<$ please insert Table 5. Probability distribution in $3 x 3$ case $>$

Without entering into a full characterization of possible equilibria, let $e^{i}$ denote education level, with five levels, $e^{0}<e^{1}<e^{2}<e^{3}<e^{4}, e^{0}=0$, where each $e^{i}$ is associated to the following expected productivity:

$$
\begin{gathered}
e=0 \quad \Rightarrow \quad E[\theta \mid e=0]=\theta_{1} \\
\left\{\begin{array}{c}
e=e^{1} \Rightarrow E\left[\theta \mid e=e^{1}\right]=\frac{p_{12} \theta_{1}+p_{21} \theta_{2}}{p_{12}+p_{21}} \\
e=e^{2} \Rightarrow E\left[\theta \mid e=e^{2}\right]=\frac{p_{13} \theta_{1}+p_{22} \theta_{2}+p_{31} \theta_{3}}{p_{13}+p_{22}+p_{31}} \\
e=e^{3} \Rightarrow E\left[\theta \mid e=e^{3}\right]=\frac{p_{23} \theta_{2}+p_{32} \theta_{3}}{p_{23}+p_{32}} \\
e=e^{4} \Rightarrow E\left[\theta \mid e=e^{3}\right]=\theta_{3}
\end{array}\right.
\end{gathered}
$$

In a manner similar to Figure 4, one can define each successive $e^{i}, i=$ $1,2,3$, as the least-cost signal such that no type has an incentive to deviate. For this to be a perfect Bayesian equilibrium, expected productivity has to be strictly increasing in the signal. If not, either types grouped at $e^{3}$ would prefer to deviate to $e^{2}$, or types grouped at $e^{2}$ would prefer to deviate to $e^{1}$, or both. This would reduce the number of educational signals from five to either four or three, producing even more bunching of types. Other than this, the analysis would be similar to equilibrium (27).

In equilibrium (27), only the extreme type $\left(\theta_{3}, \nu_{3}\right)$ goes far enough to single itself out with an educational signal. For all the types in between types $\left(\theta_{3}, \nu_{3}\right)$ and $\left(\theta_{1}, \nu_{1}\right)$, there will be some bunching (in the extreme, they will all pick the same signal), so it will not be possible to tell them perfectly apart.

Take the case where wages are sticky (if wages were flexible, we already know that employment relationships reveal no information at all). If the partially pooling equilibrium in the first period were given by (27), Will wages in the second period still be independent of education (as happened in Section 3)? 
In the second period the employer will have an incentive to dismiss workers whose productivity is lower than their wage. This will perfectly reveal the worker's exact productivity for intermediate educational level $e^{2}\left(e^{4}\right)$ : those dismissed have productivity $\theta_{1}\left(\theta_{2}\right)$, so those retained have productivity $\theta_{2}$ $\left(\theta_{3}\right)$.

However, this sign does not work perfectly for educational level $e^{3}$. The expected productivity of workers with education $e^{3}$ is either above or below $\theta_{2}$. If (i) it is equal to, or less than, $\theta_{2}$, the employer will dismiss type $\theta_{1}$ employees. This will reveal the type of dismissed workers, but not of continuing workers, of whom the market only knows that their expected productivity is

$$
E\left[\theta \mid e=e^{3}, \text { not dismissed }\right]=\frac{p_{22} \theta_{2}+p_{31} \theta_{3}}{p_{22}+p_{31}} .
$$

If the employer offers type $\theta_{3}$ less than (28), the uninformed firms will find it profitable to attract the whole pool of continuing workers, offering an $\varepsilon$ more (the analysis is similar to Figure 6). Hence, the employer will be willing to pay type $\theta_{3}$ a wage equal to expected productivity of pool, namely (28), and type $\theta_{2}$ a wage of $\theta_{2}$. Given these conditional wage offers of the informed firm, the optimal response of uninformed firms is to offer $\theta_{2}$ to the pool; if they offer more, they will lose money. This result implies that employment relationships will never allow the market to differentiate between type $\left(\theta_{3}, \nu_{1}\right)$ and type $\left(\theta_{2}, \nu_{2}\right)$, so earnings of type $\left(\theta_{3}, \nu_{1}\right)$ will depend on education in the long run.

What would happen if the expected productivity of types that pick $e^{3}$ were (ii) larger than $\theta_{2}$ ? In that case, type $\left(\theta_{2}, \nu_{2}\right)$ would be dismissed together with type $\left(\theta_{1}, \nu_{3}\right)$, so outside firms would only be willing to pay pool of dismissed workers their expected productivity. For total revelation of productivity of the lower productivity types, one would need to add more rounds.

In either case, employment relationships only lead to partial revelation of the employer's private information. However, while (ii) has transitory consequences, (i) has permanent consequences because adding more periods would not change the state of affairs. Hence, even if wages are sticky, with three types of productivity dismissals no longer produce full revelation of types. 
To determine whether the first period equilibrium in a dynamic setup will indeed be as specified in (27), one has to incorporate the long-term value of education for more able workers in the first period signaling game. If the problem of noise is strong enough, it will still be possible to find an equilibrium for which there is bunching of workers with different productivity levels in the first period.

\section{References}

[1] Akerlof, George. "The market for 'Lemons': Quality uncertainty and the market mechanism." Quarterly Journal of Economics, August 1970, 84(3): 488-500.

[2] Akerlof, George, and Yellen, Janet. "Fairness and unemployment." American Economic Review, May 1988, 78(2): 44-49

[3] Ashenfelter, Orley, and Alan Krueger. "Estimates of the economic return to schooling from a new sample of twins." American Economic Review, December 1994, 84(5): 1157-1173.

[4] Becker, Gary S. Human Capital: A Theoretical and Empirical Analysis, with Special Reference to Education. New York, NY: Columbia University Press (for NBER), 1964.

[5] Behrenz, Lars. "Who gets the job and why. An explorative study of employers' recruitment behavior." Journal of Applied Economics, November 2001, 4(2): 255-278.

[6] Bewley, Truman F. "Fairness, reciprocity, and wage rigidity." October 2002, Cowles Foundation Discussion Papers 1383, Yale University.

[7] Cho, In_Koo, and David M. Kreps. "Signaling games and stable equilibria." Quarterly Journal of Economics, May 1987, 102(2): 179-221.

[8] Edlin, Aaron S., and Chris Shannon. "Strict single crossing and the strict Spence-Mirrlees condition: A comment on monotone comparative statics." Econometrica, November 1998, 66(6): 1417-25.

[9] Fudenberg, Drew, and Tirole, Jean. Game Theory, Cambridge, MA: MIT Press, 1991. 
[10] Gibbons, Robert, and Lawrence F. Katz. "Layoffs and lemons." Journal of Labor Economics, October 1991, 9(4): 351-81.

[11] Gibbons, Robert, and Michael Waldman. "A theory of wage and promotion dynamics inside firms." Quarterly Journal of Economics, November 1999, 114(4): 1321-58.

[12] Gottschalk, Peter. "Downward nominal wage flexibility: Real or measurement error?" Review of Economics and Statistics, August 2005, 87(3): $556-68$.

[13] Jovanovic, Boyan. "Job matching and the theory of turnover." Journal of Political Economy, October 1979, 87(5): 972-990.

[14] Mincer,Jacob A., Schooling, Experience, and Earnings, New York, NY: Columbia University Press, 1974.

[15] Riley, John G. "Informational equilibrium." Econometrica, March 1979, 47(2): 331-59.

[16] Riley, John G. "Silver signals: 25 years of signaling and screening." Journal of Economic Literature, June 2001, 39(2): 432-78.

[17] Schultz, Theodore W., "Investment in human capital", American Economic Review, March 1961, 51(1): 1-17.

[18] Spence, Michael. "Job market signaling." Quarterly Journal of Economics, August 1973, 87(3): 355-379.

[19] Spence, Michael. "Signaling in retrospect and the informational structure of markets." American Economic Review, June 2002, 92(3): 434-59.

[20] Tversky, Amos, and Daniel Kahneman, "Rational choice and the framing of decisions", in Robin Hogarth and Melvin W. Reder, editors, Rational Choice. The Contrast between Economics and Psychology, Chicago, IL: University of Chicago Press, 1986.

[21] Waldman, Michael. "Job assignments, signalling and efficiency." Rand Journal of Economics, Summer 1984, 15(2): 255-67.

[22] Weiss, Andrew. "A sorting-cum-learning model of education." Journal of Political Economy, June 1983, 91(3):420-442. 
[23] Weiss, Andrew. "Human capital vs. signalling explanations of wages." Journal of Economic Perspectives, Autumn 1995, 9(4): 133-154. 
Table 1.Probability distribution in $2 x 2$ case

\begin{tabular}{llll}
\hline & & \multicolumn{2}{c}{ Taste $\nu$} \\
& $\nu_{1}$ & $\nu_{2}$ \\
Ability $\theta$ & $\theta_{1}$ & $p_{11}$ & $p_{12}$ \\
& $\theta_{2}$ & $p_{21}$ & $p_{22}$ \\
\hline
\end{tabular}

Table 2. Variance of the log of weekly earning according to age and years of schooling

\begin{tabular}{llll}
\hline & \multicolumn{3}{l}{ Years of schooling } \\
\hline Age (years) & $5-8$ & 12 & 16 \\
\hline $24-29$ & .320 & .205 & .235 \\
\hline $30-34$ & .263 & .183 & .212 \\
\hline $35-39$ & .266 & .203 & .277 \\
\hline $40-44$ & .275 & .226 & .366 \\
\hline $45-49$ & .310 & .270 & .424 \\
\hline $50-54$ & .292 & .312 & .436 \\
\hline $55-59$ & .328 & .317 & .552 \\
\hline $60-64$ & .409 & .369 & .748
\end{tabular}

Source: Mincer (1974), p. 101, weekly earnings of white nonfarm men in 1959, 1/1000 sample of the 1960 U.S. Census.

Table 3. Second period wages with public information

\begin{tabular}{ll}
\hline & Wages $w_{2}$ \\
Education & \\
- none & $\theta_{1}$ \\
- positive & $\left\{p_{12} \theta_{1}+\left(p_{21}+p_{22}\right) \theta_{2}\right\} /\left(p_{12}+p_{21}+p_{22}\right)$ \\
Employment relationship & \\
- dismissed & $\theta_{1}$ \\
- renewed & $\left\{p_{11} \theta_{1}+\left(p_{21}+p_{22}\right) \theta_{2}\right\} /\left(p_{11}+p_{21}+p_{22}\right)$ \\
\hline
\end{tabular}


Table 4. Second period wages with private information

\begin{tabular}{ll}
\hline & Wages $w_{2}$ \\
Education & \\
- none & $\theta_{1}$ \\
- positive & $\left(p_{12} \theta_{1}+p_{21} w^{1, i}+p_{22} \theta_{2}\right) /\left(p_{12}+p_{21}+p_{22}\right)$ \\
Ability & \\
- low & $\theta_{1}$ \\
- high & $\left(p_{21} w^{1, i}+p_{22} \theta_{2}\right) /\left(p_{21}+p_{22}\right)$ \\
\hline
\end{tabular}

Table 5. Probability distribution in $3 x 3$ case Taste $\nu$

$\begin{array}{lll}\nu_{1} & \nu_{2} & \nu_{3}\end{array}$

$\theta_{1} \quad p_{11} \quad p_{12} \quad p_{13}$

Ability $\theta \quad \theta_{2} \quad p_{21} \quad p_{22} \quad p_{23}$

$\theta_{3} \quad p_{31} \quad p_{32} \quad p_{33}$ 


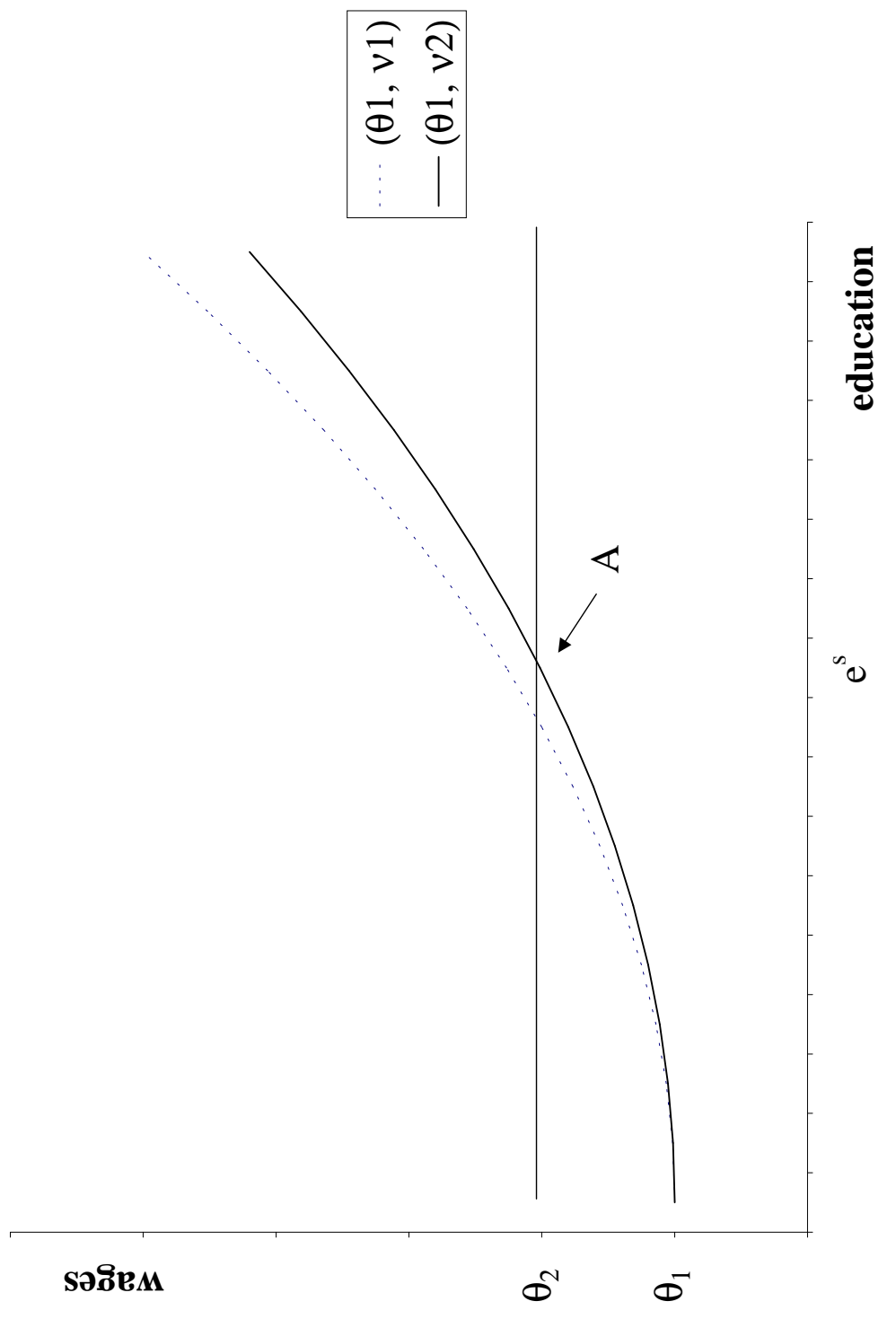

Figure 1: Single crossing: Separating equilibrium 


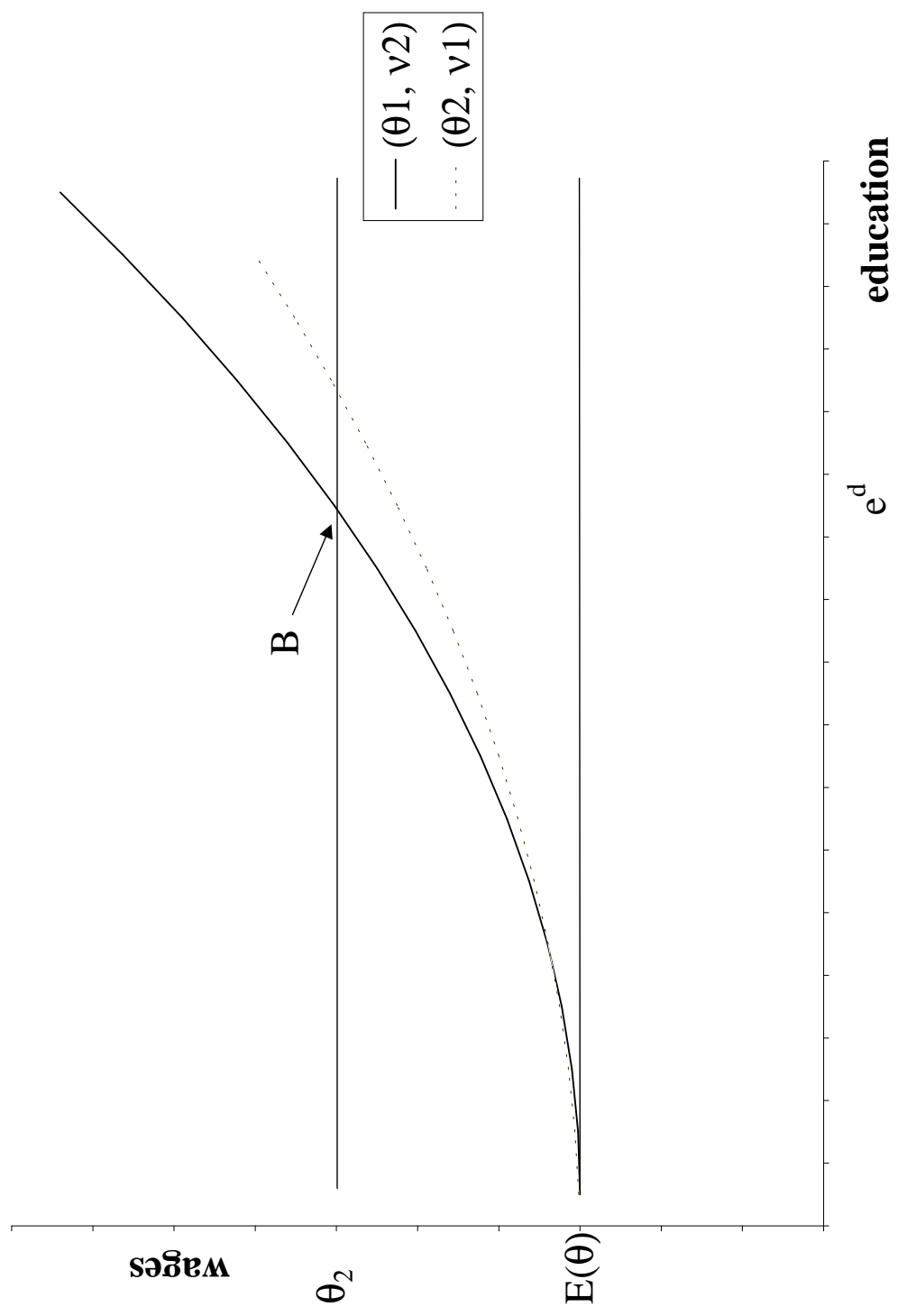

Figure 2: Single crossing: No pooling equilibrium 


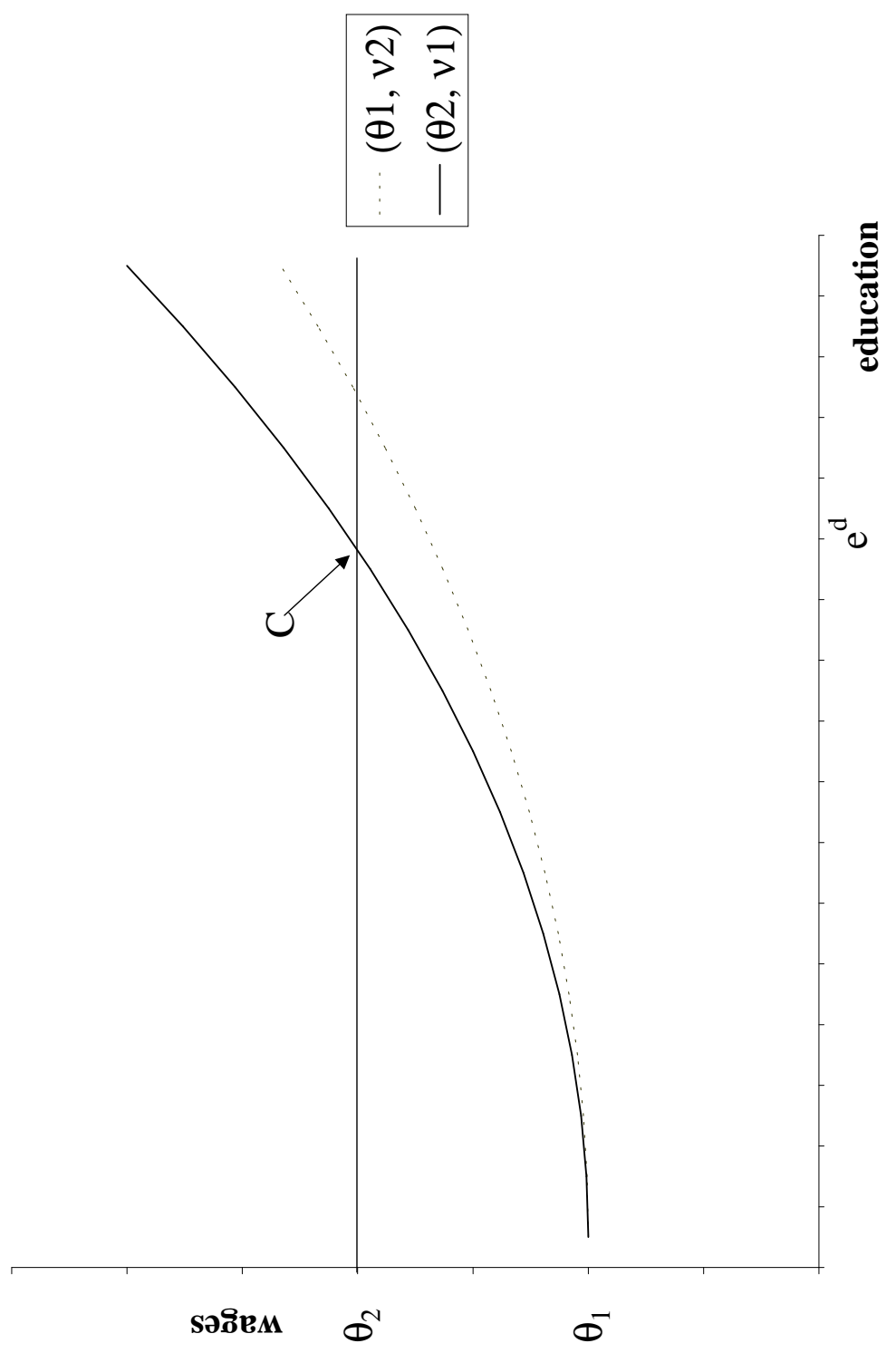

Figure 3: No single crossing: No separating equilibrium 


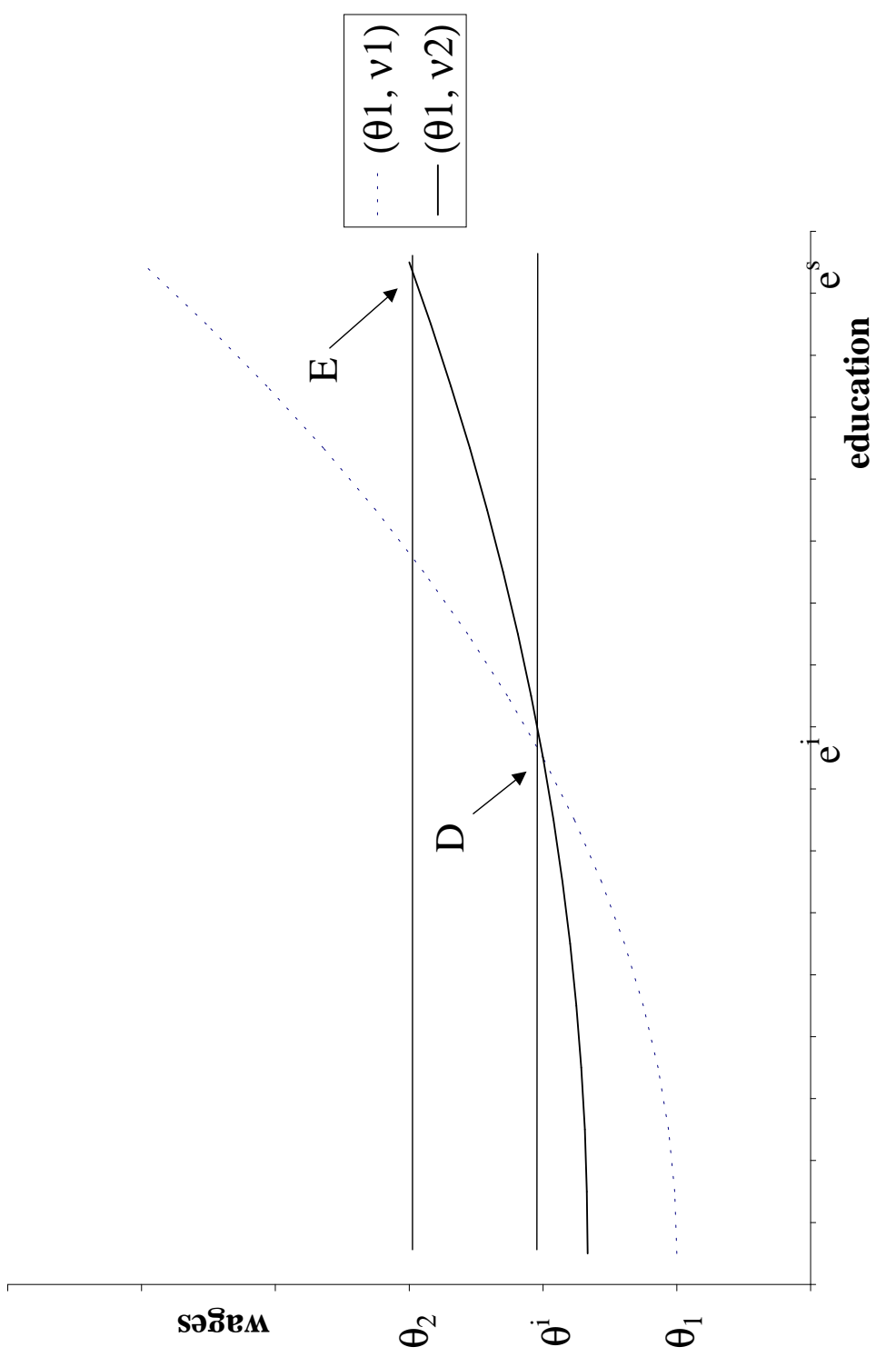

Figure 4: No single crossing: Partially pooling equilibrium 


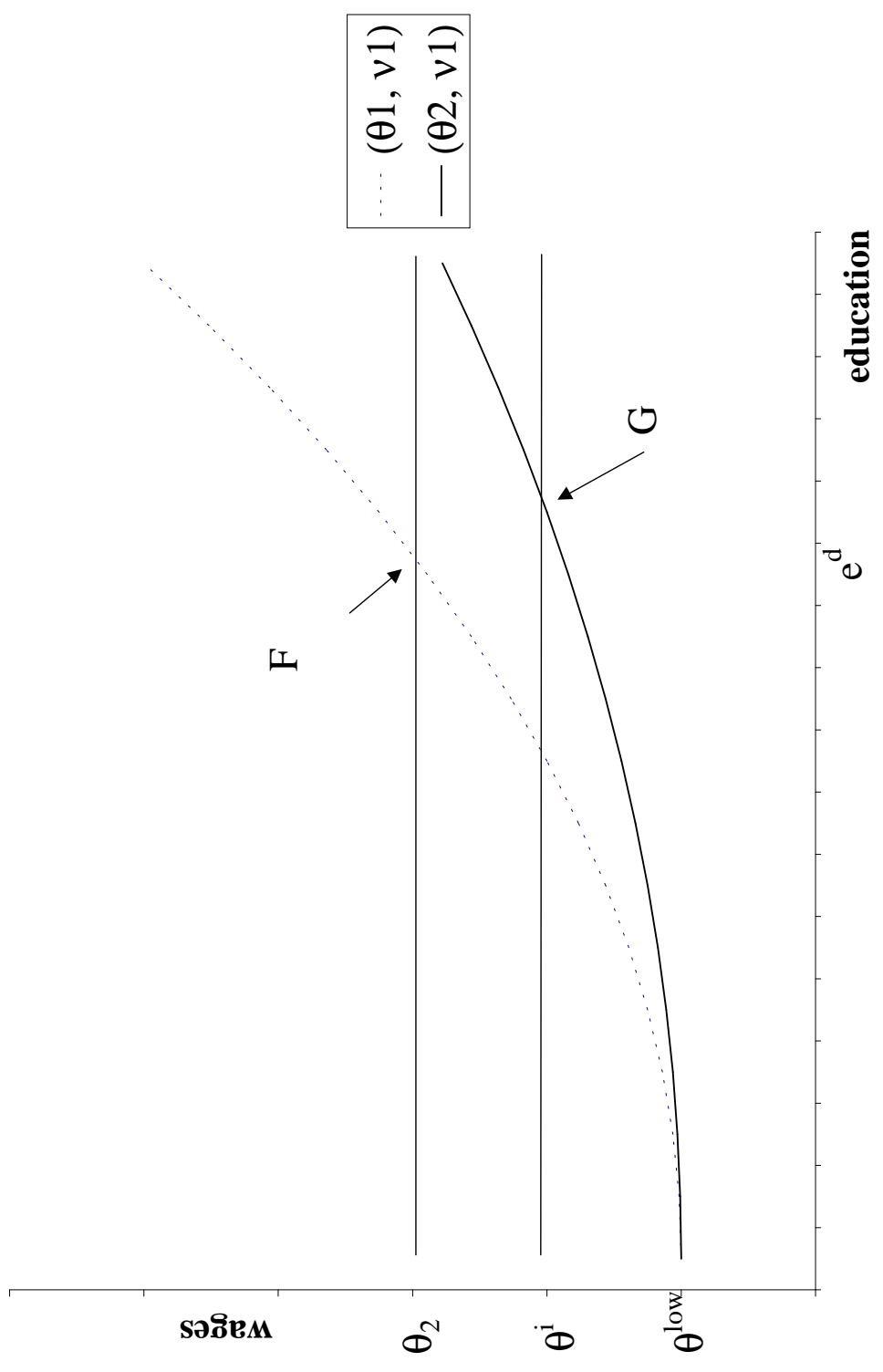

Figure 5: No single crossing: Alternative partially pooling equilibrium? 


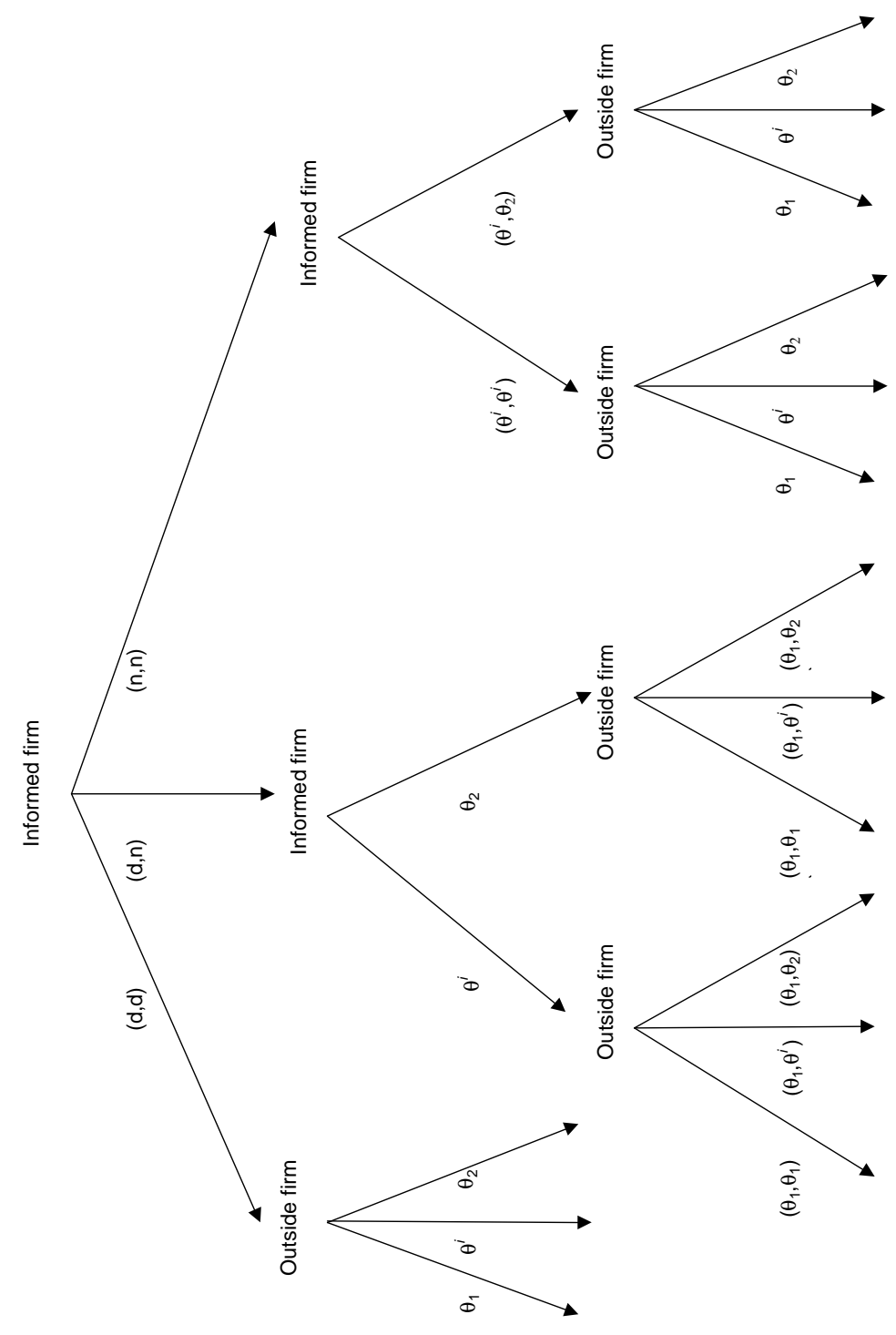

Figure 6: Employment and wage policies with sticky wages 


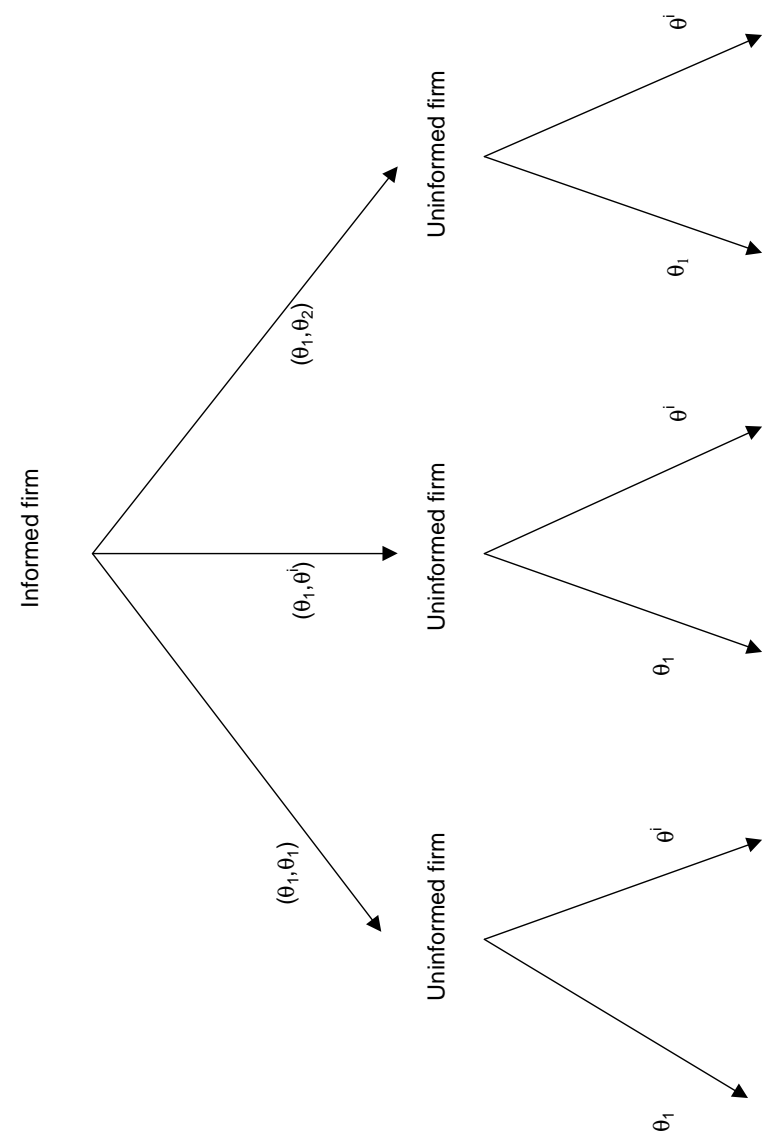

Figure 7: Wage policies with flexible wages 


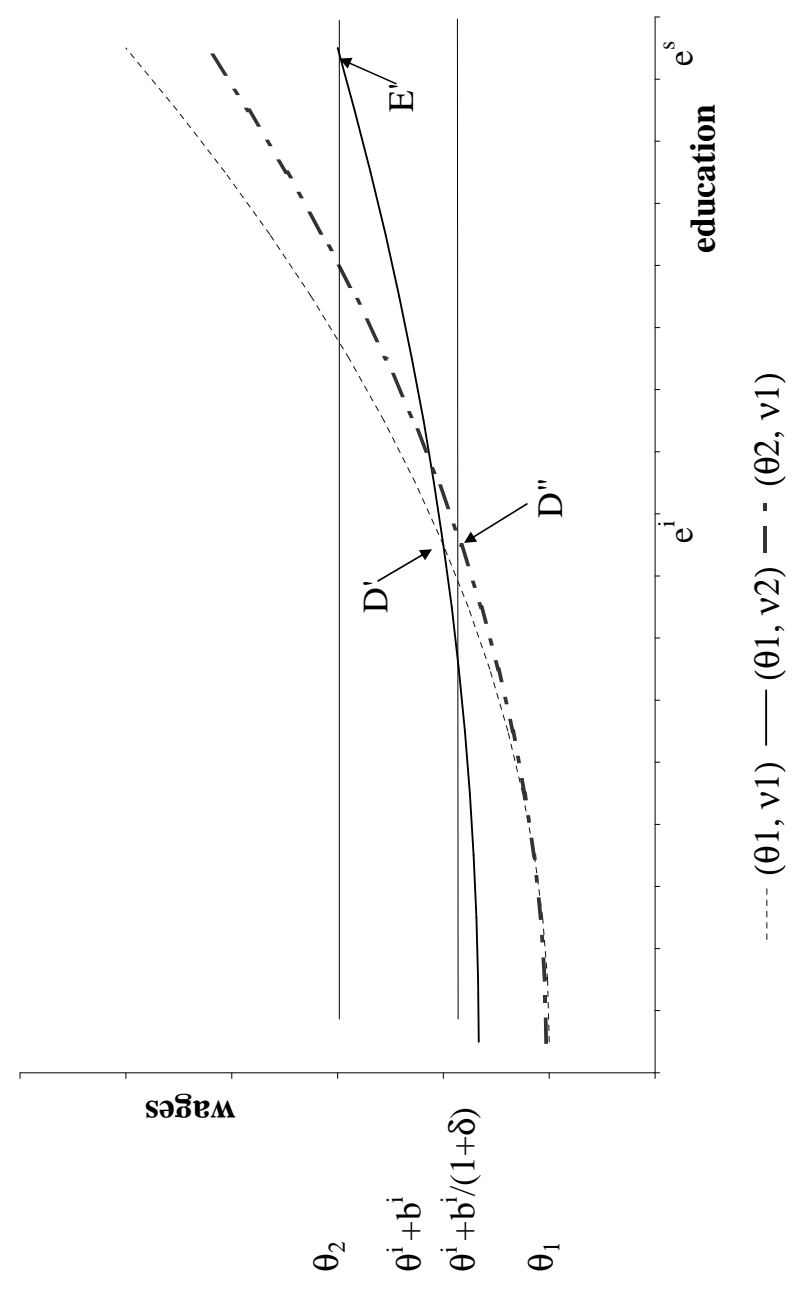

Figure 8: No single-crossing: Partially pooling equilibrium in two-period model 